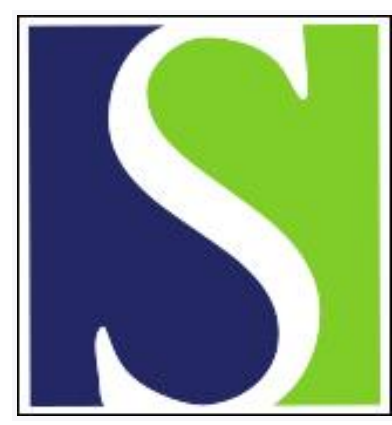

Scand J Work Environ Health 2000;26(2):112-117

https://doi.org/10.5271/sjweh.520

Issue date: Apr 2000

Incidence rates of malignant mesothelioma in Denmark and predicted future number of cases among men

by Kjærgaard J, Andersson M

Key terms: age-cohort model; epidemiology

This article in PubMed: www.ncbi.nlm.nih.gov/pubmed/10817376

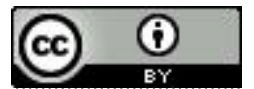




\title{
Incidence rates of malignant mesothelioma in Denmark and predicted future number of cases among men
}

\author{
by Jesper Kjærgaard, MD, ${ }^{1}$ Michael Andersson, DrMedSC ${ }^{\dagger}$
}

\begin{abstract}
Kjærgaard J, Andersson M. Incidence rates of malignant mesothelioma in Denmark and predicted future number of cases among men. Scand J Work Environ Health 1999;26(2):112-117.

Objectives This study analyzed the incidence rates of malignant mesothelioma in Denmark in order to predict the future number of cases that will occur among Danish men.

Methods The 1912 cases of malignant mesothelioma reported to the Danish Cancer registry in 1943-1993 were analyzed in order to describe current incidence rates. By a Poisson regression model the relative risks of synthetic birth cohorts were estimated and used in the prediction of the future number of cases that will occur among Danish men.

Results The incidence rate increased to 1.33 per 100000 person-years in $1983-1987$ among men and to 0.51 in 1973 - 1977 among women. From the Poisson regression model, the risk for birth cohorts of men, relative to the 1940-1944 cohort, peaked in the 1940-1944 cohort and decreased to 0.57 in the $1950-1954$ cohort. The agespecific incidence rate peaked at 246 per 100000 person-years in the age group 80-84 years. The future annual number of mesothelioma cases is expected to peak around 2015 with 93 cases among men born before 1955 .

Conclusions The fit of the models was not ideal, but with careful interpretation of the results, it was concluded that a further increase in the number of mesothelioma cases can be expected, and the effect of regulating the environmental exposure to asbestos cannot be expected within the next $10-15$ years.
\end{abstract}

Key terms age-cohort model, epidemiology.

About 65 cases of malignant mesothelioma are reported in Denmark annually (1). This rare cancer is strongly associated with exposure to asbestos $(2,3)$. Hence the use of asbestos in the Danish industry was banned with few exceptions in $1979(4,5)$. It is estimated that more than half the mesothelioma cases are caused by asbestos (6). Asbestos fibers are used in industry, in Denmark mostly in shipyards, for insulating materials, pipe fittings, and brake linings for trains and automobiles (3). Although the carcinogenicity of especially the amphibole asbestos fibers has been known since the 1960s, the use of asbestos in industry was continued for several years, up until the legislation prohibiting it.

The effect of banning industrial asbestos use has not yet appeared in the published incidence rates from the registry (7), perhaps due to the latency of 30 years or more from exposure to diagnosis of the disease $(8,9)$.

The Danish Cancer Registry was founded in 1943 and collects detailed information on diagnosed cancer cases (10).
Recent publications have predicted an alarming increase in mesothelioma deaths over the next 30 years by statistical modeling $(11-13)$. In the present study, we aim to demonstrate an effect of the decreased exposure level through a log-linear regression analysis of the birth cohort and the period of diagnosis for Danish men, with a prediction of incidence until the year 2040 . The methods of the analysis are comparable with those used in recent studies of mesothelioma trends $(11-14)$.

\section{Materials and methods}

Data from the Danish Cancer Register were used in the study. The completeness and accuracy of the register is considered to be high $(1,10)$.

All cases of malignant mesothelioma diagnosed and coded as such in the period 1943-1993 were identified according to the modified ICD-7 classification (pleura,

1 Institute of Cancer Epidemiology, Danish Cancer Registry, Danish Cancer Society, Copenhagen, Denmark.

Reprint requests to: Dr Jesper Kjærgaard, Institute of Cancer Epidemiology, Danish Cancer Registry, Danish Cancer Society, Strandboulevarden 49, DK-2100 Copenhagen $\emptyset$, Denmark. [E-mail: jesperk@ cancer.dk] 
peritoneum and pericardium) in use prior to 1978 by the International Classification of Diseases (ICD) $(1,15)$ and afterwards according to the ICD-O (16) through a combination of the morphological and topographical codes. Four cases recorded as mesothelioma of the scrotum were excluded.

For each case gender, date of birth, month and year of diagnosis, and the ICD-7 or ICD-O codes were extracted and cases with ICD-O codes were converted to ICD-7 codes by a computerized conversion program into the locations pleura, peritoneum or pericardium. For calculating the incidence rates, the age distribution in the Danish population was determined through the aid of Statistics Denmark (17). Incidence rates directly standardized according to the World Standard Population (WSTP) (18) and the $95 \%$ confidence intervals $(95 \% \mathrm{CI})$ were calculated on the assumption of a Poisson distribution of the observed cases (19).

The distribution of malignant mesothelioma among men by age and year of birth was analyzed by Poisson regression, as done by Peto and his co-workers (14). Birth cohorts were computed as synthetic cohorts according to age and date at diagnosis, each case being assigned to 1 birth cohort. Person-years at risk (PYR) were constructed in a similar way. Age-specific incidence rates, $\mathrm{k}_{\mathrm{a}}$, were estimated for the age groups $30-34$ years $(a=1)$ to 85 89 years $(a=12)$. Birth-cohort-specific relative risks, $c_{b}$, were calculated for the cohorts born in $1875-1879(b=1)$ to $1950-1954(b=16)$. The relative risk for the 1940 1944 cohort, $c_{14}$, was set at unity.

The predicted annual age-specific incidence rates were calculated as the product of the age-specific rate and the relative risk of the birth cohort, $\mathrm{k}_{\mathrm{a}} \cdot \mathrm{c}_{\mathrm{b}}$. The fitted numbers of cases were calculated as the product of the predicted age-specific incidence rates and the personyears in the cell. Goodness-of-fit was evaluated by the Pearson's $\chi^{2}$-test, and the P-values of the fit were computed $(20,21)$.

The predicted rates were used to estimate the number of future mesothelioma cases. The estimate was made for men born before 1955 and for all men, assuming that the relative risk for cohorts born after 1955 was $50 \%$ of the 1940 - 1944 cohort. This approach was used due to the very few observed cases in the younger birth cohort, since the lack of cases made the risk estimates unreliable. Population prognoses of Statistics Denmark (17) were used for calculating the estimated number of cases. The asbestos consumption in Denmark was used for estimating the exposure to asbestos (22).

For comparison a similar analysis was done using the variables period of diagnosis and age at diagnosis. The age groups were the same, and the periods, $\mathrm{p}_{\mathrm{c}}$, were $\mathrm{c}=1$ for $1943-1947$, to $c=10$ for the period $1988-1992$. The last period $\left(\mathrm{p}_{11}\right)$ only contained data from 1993 . The period 1988-1992 ( $\left.\mathrm{p}_{10}\right)$ was used as the basis for comparison because most of the cases were diagnosed during this period.

\section{Resulis}

In table 1 the total number of cases of malignant mesothelioma is shown according to their location among the men and women. The proportion of pleural mesotheliomas was greater for the men $(89.5 \%)$ than the women $(71.3 \%)$, and the proportion of the peritoneal tumors was greater among the women than among the men. Tumors of the pericardium comprised less than $2 \%$ of the total for both genders.

The incidence rate for the men was higher than that of the women, and it increased from 0.10 per 100000 person-years in 1943-1947 to 1.32 (95\% CI $0.47-$ 2.17) per 100000 person-years in 1983-1987, and then decreased to $1.31(0.46-2.15)$ per 100000 person-years in 1988-1992 (figure 1). The incidence rate for the women increased to 0.51 per 100000 in 1973-1977, and then decreased to 0.27 in $1988-1992$.

Table 2 shows the age- and birth-cohort-specific observed number (fitted number below) of cases of malignant mesothelioma among the men. Under the birth-cohort intervals the estimated birth-cohort-specific relative risks are shown, rising to a maximum (1.00) in the cohort born in 1940-1944. The estimated age-specific rates are shown under the corresponding age interval. The rate is 0.66 per 100000 person-years in the age group $30-34$ years, and it increases steadily to 246 per 100000 person-years in the group $80-84$ years. As an evaluation of the goodness-of-fit, the difference between the observed and the fitted number of cases was computed by Pearson's $\chi^{2}$-test $\left(\chi^{2}=109, \mathrm{df}=92, \mathrm{P}=0.11\right)$.

Figure 2 shows the annual observed number of cases of malignant mesothelioma in quinquennia defined by midyear. Note that the period 1993-1997 only contains data of the year 1993. The estimated annual number of cases is shown for comparison, and this graph is extended into the predicted annual numbers of cases in the years

Table 1. Number of cases of malignant mesothelioma in Denmark in 1943-1993. (ICD = International Classification of Diseases)

\begin{tabular}{lrrrrr}
\hline Site of tumor & \multicolumn{2}{c}{ Men } & & \multicolumn{2}{c}{ Women } \\
\cline { 2 - 3 } \cline { 5 - 6 } & $N$ & $\%$ & & $N$ & $\%$ \\
\hline Pleura & 1200 & 89.5 & & 407 & 71.3 \\
Peritoneum & $123^{\mathrm{a}}$ & 9.1 & & 154 & 27.0 \\
Pericardium & 18 & 1.3 & & 10 & 1.8 \\
Total & 1341 & 100 & & 571 & 100 \\
\hline
\end{tabular}

a Including one tumor coded as the ICD-7th revision code 199.3: unspecified site, abdomen. 


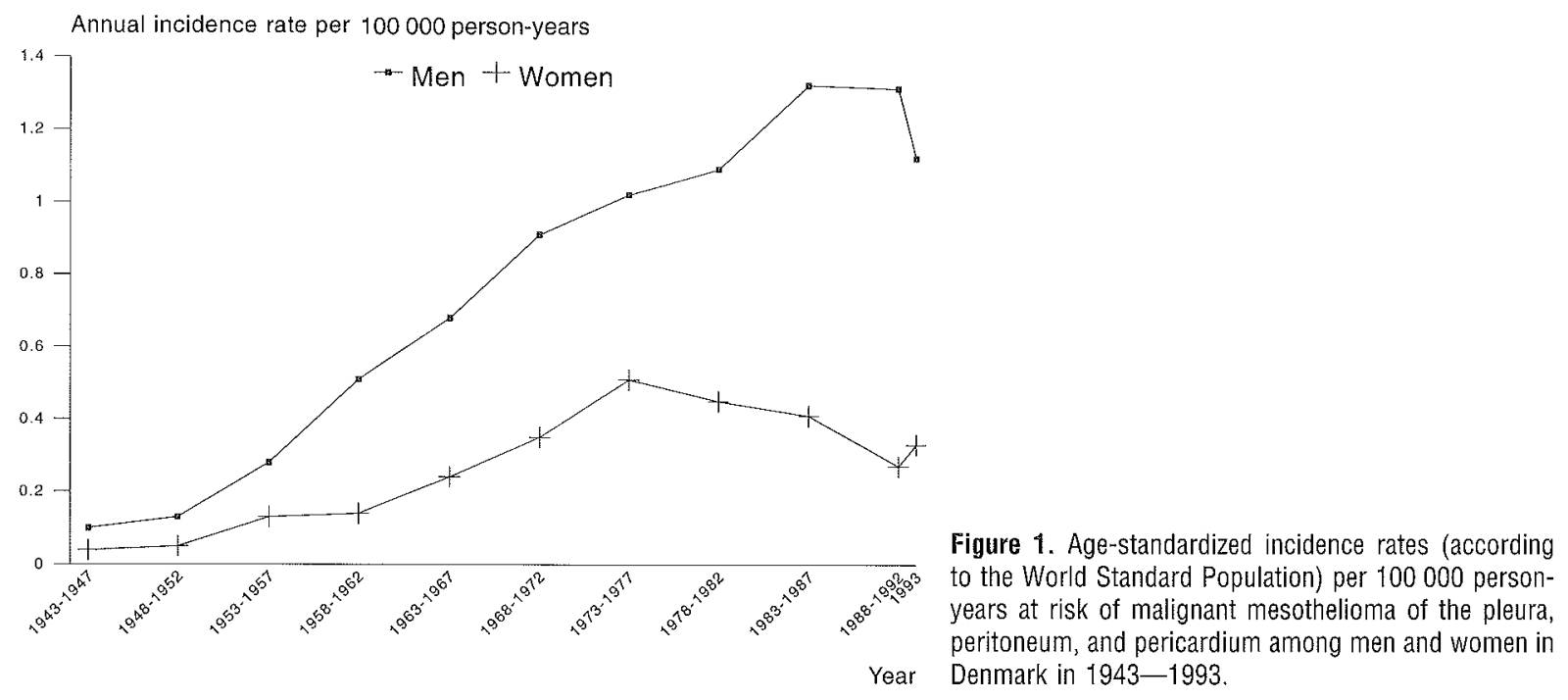

Table 2. Cases of malignant mesothelioma among Danish men in 1943-1993 and the fitted numbers based on the birth cohort analysis. Each cell shows the observed $(0)$ number of mesothelioma cases next to the fitted (F) number derived from the birth cohort model by multiplying the population person-years (not shown) by the product of $k_{a}$ and $c_{b}$. Birth cohort, $c_{b}$, is defined by midyear.

\begin{tabular}{|c|c|c|c|c|c|c|c|c|c|c|c|c|c|c|c|c|c|c|c|c|c|c|c|c|c|}
\hline \multirow[t]{3}{*}{ Year of birth } & \multirow{3}{*}{$\begin{array}{c}\text { Relative } \\
\text { risk }\end{array}$} & \multicolumn{24}{|c|}{ Age group (years) ${ }^{a}$} \\
\hline & & \multicolumn{2}{|c|}{$\begin{array}{c}30-34 \\
(0.66)\end{array}$} & \multicolumn{2}{|c|}{$\begin{array}{c}35-39 \\
(2.22)\end{array}$} & \multicolumn{2}{|c|}{$\begin{array}{c}40-44 \\
(4.18)\end{array}$} & \multicolumn{2}{|c|}{$\begin{array}{c}45-49 \\
(7.76)\end{array}$} & \multicolumn{2}{|c|}{$\begin{array}{c}50-54 \\
(19.7)\end{array}$} & \multicolumn{2}{|c|}{$\begin{array}{c}55-59 \\
(30.8)\end{array}$} & \multicolumn{2}{|c|}{$\begin{array}{c}60-64 \\
(57.3)\end{array}$} & \multicolumn{2}{|c|}{$\begin{array}{c}65-69 \\
(83.6)\end{array}$} & \multicolumn{2}{|c|}{$\begin{array}{c}70-74 \\
(130)\end{array}$} & \multicolumn{2}{|c|}{$\begin{array}{c}75-79 \\
(185)\end{array}$} & \multicolumn{2}{|c|}{$\begin{array}{c}80-84 \\
(246)\end{array}$} & \multicolumn{2}{|c|}{$\begin{array}{c}85-89 \\
(220)\end{array}$} \\
\hline & & 0 & $\mathrm{~F}$ & 0 & $F$ & 0 & $\mathrm{~F}$ & 0 & $\mathrm{~F}$ & 0 & $\mathrm{~F}$ & 0 & $\mathrm{~F}$ & 0 & $\mathrm{~F}$ & 0 & $F$ & 0 & $\mathrm{~F}$ & 0 & $\mathrm{~F}$ & 0 & $\mathrm{~F}$ & 0 & $\mathrm{~F}$ \\
\hline $1875-1879$ & 0.043 & .. & & & & .. & & .. & & & & & & & & 2 & 2.3 & 2 & 3.0 & 1 & 3.1 & 6 & 2.5 & 1 & 0.9 \\
\hline $1880-1884$ & 0.089 & $\begin{array}{l}. . \\
. .\end{array}$ & & $\begin{array}{l}. . \\
. .\end{array}$ & & $\begin{array}{l}. . \\
. .\end{array}$ & & $\begin{array}{l}. . \\
. .\end{array}$ & & .. & & & & $\ddot{5}$ & 4.1 & 1 & 5.3 & 4 & 6.8 & 10 & 7.1 & 7 & 5.5 & 4 & $\begin{array}{l}0.5 \\
2.2\end{array}$ \\
\hline $1885-1889$ & 0.145 & .. & & .. & &.. & & .. & & & & $\ddot{1}$ & 4.2 & 4 & 7.3 & 6 & 9.4 & 141 & 12.0 & 16 & 12.3 & 12 & 9.8 & 6 & 4.1 \\
\hline $1890-1994$ & 0.158 & .. & & .. & & .. & &.. & & 1 & 3.4 & 1 & 5.0 & 6 & 8.5 & 111 & 11.1 & 151 & 14.0 & 18 & 14.4 & 16 & 11.7 & 5 & 4.9 \\
\hline $1895-1899$ & 0.195 & .. & & .. & &.. & & $\because$ & 1.9 & 3 & 4.6 & 6 & 6.9 & 131 & 11.8 & 191 & 15.1 & 19 & 18.9 & 18 & 19.4 & 15 & 15.7 & 8 & 6.7 \\
\hline $1900-1904$ & 0.234 & .. & & .. & & - & 1.4 & 2 & 2.5 & 5 & 6.0 & 8 & 9.0 & 191 & 15.4 & 261 & 19.7 & 262 & 24.7 & 22 & 25.2 & 20 & 20.3 & 5 & 8.8 \\
\hline $1905-1909$ & 0.295 & .. & & - & 1.0 & 1 & 1.9 & $\overline{4}$ & 3.4 & 6 & 8.3 & 111 & 12.4 & 202 & 21.2 & 342 & 27.1 & 413 & 34.0 & 33 & 34.9 & 24 & 28.5 & 1 & 2.4 \\
\hline $1910-1914$ & 0.341 & - & 0.4 & - & 1.2 & - & 2.2 & 1 & 4.0 & 7 & 9.9 & 231 & 14.7 & 292 & 25.2 & 373 & 32.2 & 434 & 40.7 & 39 & 42.4 & 1 & 7.1 & .. & \\
\hline $1915-1919$ & 0.373 & - & 0.4 & - & 1.3 & 4 & 2.3 & 4 & 4.3 & 131 & 10.5 & 221 & 15.7 & 232 & 26.8 & 353 & 34.2 & 36 & 43.4 & 11 & 9.0 & .. & & .. & \\
\hline $1920-1924$ & 0.522 & 1 & 0.5 & 2 & 1.8 & 5 & 3.3 & 10 & 6.0 & 171 & 14.9 & 212 & 22.1 & 433 & 37.7 & 38 & 48.3 & 101 & 12.4 &.. & &.. & & $\begin{array}{l}. . \\
. .\end{array}$ & \\
\hline $1925-1929$ & 0.574 & 1 & 0.5 & 4 & 1.8 & 3 & 3.4 & 8 & 6.2 & 171 & 15.3 & 202 & 22.6 & 403 & 38.9 & 61 & 10.3 & .. & &.. & & .. & & .. & \\
\hline $1930-1934$ & 0.601 & - & 0.6 & 2 & 1.9 & 1 & 3.5 & 10 & 6.4 & 181 & 15.6 & 252 & 23.2 & 3 & 7.9 &.. & & .. & &.. & & .. & & .. & \\
\hline $1935-1939$ & 0.785 & 2 & 0.8 & 1 & 2.7 & 5 & 5.0 & 10 & 9.0 & 242 & 22.2 & 4 & 6.3 & .. & & $\begin{array}{l}. . \\
. .\end{array}$ & & $\begin{array}{l}. . \\
. .\end{array}$ & & ... & & $\begin{array}{l}. . \\
. .\end{array}$ & & .. & \\
\hline $1940-1944$ & 1.00 & 2 & 1.3 & 4 & 4.2 & 12 & 7.9 & 101 & 4.3 & 6 & 6.3 &.. & & .. & & .. & &.. & & ... & & $\begin{array}{l}. . \\
.\end{array}$ & & .. & \\
\hline $1945-1949$ & 0.617 & - & 0.9 & 5 & 2.8 & 5 & 5.3 & 1 & 2.0 & & & .. & &.. & & .. & & .. & & $\begin{array}{l}. . \\
. .\end{array}$ & & .. & & .. & \\
\hline $1950-1954$ & 0.568 & - & 0.7 & 3 & 2.4 & 1 & 0.9 &.. & & .. & &.. & &. & & .. & & .. & &.. & & .. & & .. & \\
\hline
\end{tabular}

a Incidence rate $-k_{a}$ per 100000 person-years in parentheses.

2000-2040. The predicted annual number among men born before 1955 peaks around the year 2015 by 93 cases. For all men, when a relative risk of $50 \%$ of that of the 1940-1944 cohort for men was assumed, a peak in 2020 by 110 annual cases was found. The figure levels at about 80 annual cases over the years $2030-2040$.

The annual asbestos consumption in Denmark in $1910-1993$ is shown in bars in figure 2. The import was greatest during 1965-1979 (approximately 30000 tons per year) and decreased to 704 tons in $1990-1993$.

Table 3 shows, like table 2, the observed number of malignant mesotheliomas above the expected number. The numbers were derived from the model of period of diagnoses and age at diagnosis. The maximum effect of period occurs for the period 1983-1988, which had a relative risk of 1.01 , the goodness-of-fit having been evaluated by Pearson's $\chi^{2}$-test $\left(\chi^{2}=80.5\right.$, df=97, $P=0.89$ ).

An analysis of the variables birth cohort, age, and period of diagnosis was also done, and it gave no better fit.

\section{Discussion}

The data of Danish cancer cases diagnosed since 1943, as registered in the Danish Cancer Register, is almost complete (10). However some misclassification of mesothelioma cases has occurred (23), and this misclassification complicates the interpretation of the results. 


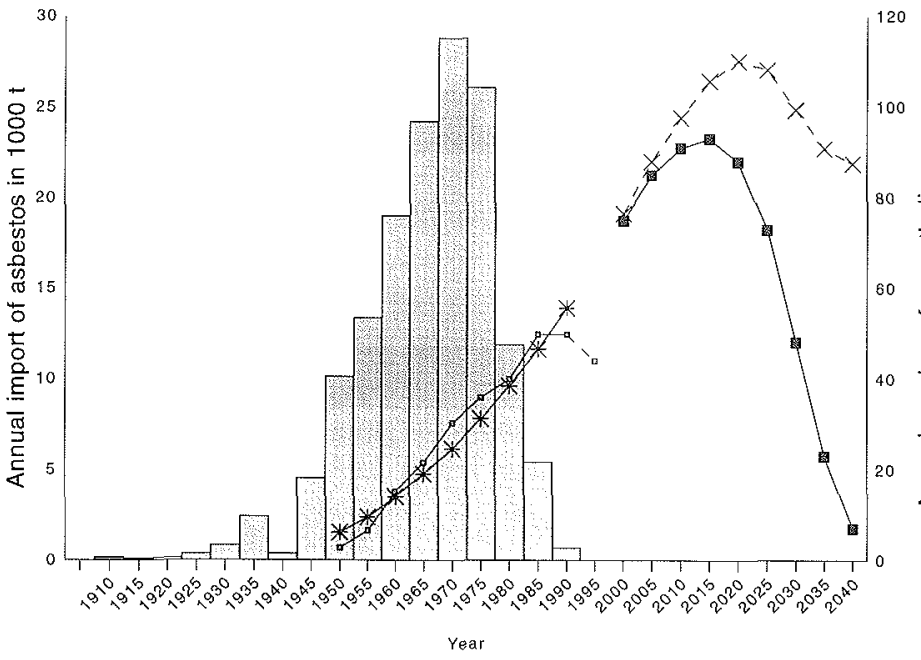

Figure 2. Observed (Obs) and expected (Exp) (fitted) number of cases of malignant mesothelioma in 1943993. Values of the annual number of cases for men born before 1955 and for all men predicted on the assumption of a relative risk of $50 \%$ of the $1940-1945$ birth cohort. The annual asbestos consumption in Denmark in 19101993 is shown as the 5-year average in bars.

Table 3. Cases of malignant mesothelioma among Danish men in 1943-1993 and the fitted numbers based on a period-of-diagnosis analysis. Each cell shows the observed $(0)$ number of mesothelioma cases next to the fitted $(F)$ number derived from the period-ofdiagnosis model by multiplying the population person-years (not shown) by the product of $k_{a}$ and $p_{c}$.

\begin{tabular}{|c|c|c|c|c|c|c|c|c|c|c|c|c|c|c|c|c|c|c|c|c|c|c|c|c|c|}
\hline \multirow[t]{3}{*}{ Year of birth } & \multirow{3}{*}{$\begin{array}{c}\text { Relative } \\
\text { risk }\end{array}$} & \multicolumn{24}{|c|}{ Age group (years) ${ }^{\mathrm{a}}$} \\
\hline & & \multicolumn{2}{|c|}{$\begin{array}{r}30-34 \\
(0.66)\end{array}$} & \multicolumn{2}{|c|}{$\begin{array}{c}35-39 \\
(2.22)\end{array}$} & \multicolumn{2}{|c|}{$\begin{array}{c}40-44 \\
(4.18)\end{array}$} & \multicolumn{2}{|c|}{$\begin{array}{c}45-49 \\
(7.76)\end{array}$} & \multicolumn{2}{|c|}{$\begin{array}{c}50-54 \\
(19.7)\end{array}$} & \multicolumn{2}{|c|}{$\begin{array}{c}55-59 \\
(30.8)\end{array}$} & \multicolumn{2}{|c|}{$\begin{array}{c}60-64 \\
(57.3)\end{array}$} & \multicolumn{2}{|c|}{$\begin{array}{c}65-69 \\
(83.6)\end{array}$} & \multicolumn{2}{|c|}{$\begin{array}{c}70-74 \\
(130)\end{array}$} & \multicolumn{2}{|c|}{$\begin{array}{c}75-79 \\
(185)\end{array}$} & \multicolumn{2}{|c|}{$\begin{array}{c}80-84 \\
(246)\end{array}$} & \multicolumn{2}{|c|}{$\begin{array}{c}85-89 \\
(220)\end{array}$} \\
\hline & & 0 & $\mathrm{~F}$ & 0 & $\mathrm{~F}$ & 0 & $\mathrm{~F}$ & 0 & $\mathrm{~F}$ & 0 & $\mathrm{~F}$ & 0 & $F$ & 0 & $F$ & 0 & $\mathrm{~F}$ & 0 & $F$ & 0 & $F$ & 0 & $F$ & 0 & $F$ \\
\hline & & & 0. & & 0. & - & 0.5 & - & 0.8 & 1 & 1. & & 1. & & & & & & & & & & & & \\
\hline & & & 0 & & & 1 & 0. & 2 & & & 1. & & 2 & & 2 & & & 2 & 2.6 & & & & & .. & \\
\hline 957 & 0.202 & 1 & 0.2 & & 0.7 & - & 1.2 & 4 & 2.0 & 5 & 3.8 & 6 & 4.3 & 5 & 5.6 & 6 & 5.6 & 4 & 5.4 & 1 & 4.2 & & & & \\
\hline 1962 & 04 & 1 & 0.4 & 2 & 1.3 & 4 & 2.3 & 1 & 4.1 & & 8.2 & & 9.3 & 131 & 12.4 & 111 & 12.0 & 141 & 11.4 & 10 & 9.1 & & 5.4 & & \\
\hline 967 & 0.522 & & 0.5 & 4 & 1.6 & 5 & 3.0 & 4 & 5.2 & 71 & 1.0 & 111 & 3.3 & 191 & 17.6 & 191 & 17.3 & 151 & 16.0 & & 12.7 & & 7.6 & 1 & 2.2 \\
\hline 972 & 0.6 & 2 & 0.8 & 2 & 2.1 & 3 & 3.8 & 10 & 7.0 & 131 & & & & 202 & & 262 & & 192 & & 181 & & & 1.0 & 4 & 3.3 \\
\hline & 0.78 & 2 & 1.1 & 1 & 2.6 & 1 & 4.2 & 8 & 7.3 & 171 & & 221 & 9.9 & 292 & 29.6 & 343 & 30.6 & 262 & 28.4 & 182 & 22.2 & & 6 & 6 & 4.2 \\
\hline 982 & 0.838 & & 1.3 & 4 & 3.5 & 5 & 4.9 & 10 & & 171 & & 212 & & 233 & 31.0 & 373 & & 413 & 33.4 & 222 & 25.8 & & & 5 & 5.1 \\
\hline & 1.01 & & 1.4 & 5 & 4.5 & 12 & 7.3 & 101 & 0.1 & 181 & 9.2 & 202 & 4.2 & 433 & 37.5 & 353 & 39.6 & 434 & 41.7 & 333 & 34.2 & & 6 & 8 & 6.6 \\
\hline 992 & &. & & 3 & 4.1 & 5 & 7.9 & 101 & & 242 & & 252 & & 403 & 34.8 & 383 & 39.6 & 364 & 40.4 & 393 & 35.7 & 242 & 2.8 & 5 & 7.2 \\
\hline 199 & 0.882 & . & & & & 1 & 1.3 & 1 & 2.5 & 6 & 4.0 & 4 & 4.3 & 3 & 6.0 & 6 & 6.8 & 10 & 7.3 & 11 & 6.1 & & 4.3 & 1 & 1.4 \\
\hline
\end{tabular}

a Incidence rate $-k_{a}$ per 100000 person-years in parentheses.

Some cases of malignant mesothelioma were diagnosed at autopsy. In a study (7) of the mesothelioma incidence rate in Denmark in 1943-1992, 25\% and 29.5\% of the cases among men and women, respectively, had a survival of 0 months, and most of these are likely to have been diagnosed at autopsy even though perioperative mortality might have been of some importance. During the 1970 s, and particularly after the procedures changed for the autopsy requests in 1990, the rate of autopsy in Denmark declined from $45 \%$ in 1970 to $16 \%$ in 1990 (24). A Danish study concluded that a decrease in the frequency of autopsy leads to an underestimation of the incidence rate of rare cancers (25). Malignant mesothelioma is such a cancer.

The 12-13-fold increase in the male incidence rate of malignant mesothelioma since the beginning of registration until today is unlikely to be an artefact (26). Similar increases have been seen in other countries $(6$, $13,14,27)$.

The larger fraction of mesothelioma of the peritoneum in women may be due to a misclassification of cancers of the ovaries. In a Danish study about $30 \%$ of the peritoneal mesothelioma cases among women were found to be misclassified ovarian or gastrointestinal tumors (23).

In the Poisson regression analysis, a log-linear model with the parameters age and birth cohort was chosen because of the possibility of comparison with the results of Peto and his co-workers (14). The analysis was based only on cases among men because of the relatively low number of cases among women (table 1) and the possible misclassification of peritoneal mesotheliomas among 
women (23). Because asbestos is considered to be the only important risk factor for malignant mesothelioma, other possible risk factors were omitted from the model. Smoking was also omitted because of no evidence of an effect on the risk of malignant mesothelioma in contrast to lung cancer, for which an important synergistic effect has been demonstrated (28).

The goodness-of-fit, evaluated by Pearson's $\chi^{2}$-test (21), suggests that the age-birth cohort model has a poor fit, with a nearly significant P-value of 0.11 of the difference between the observed and the estimated values. This occurrence could be due to the period of diagnosis being a stronger parameter than the cohort of birth. As in the study by Peto and his co-workers (14) the number of cases and the short period at risk in the younger age groups, who have not had the same exposure level as the older groups, make the estimates for these groups uncertain. The structure of the synthetic birth cohorts makes the small changes in the data even harder to detect (21).

The results of the study by Peto and his co-workers (14) are based on mortality data, but the average survival time, being only about 7 months after the diagnosis (7), makes the mortality and the incidence rates comparable. The prediction of future incidence rates for malignant mesothelioma was done in a manner similar to that of Peto and his co-workers (14).

The prediction of the number of new cases of malignant mesotheliomas is based on the assumption that men born after 1955 have half the risk of the $1940-1944$ cohort. This assumption is made under the consideration that banning the use of asbestos in the industry and improving the work environment cannot eliminate all exposure to asbestos, and similar assumptions have been made in recent studies $(11,12,14)$.

The risk of mesothelioma from asbestos in the work environment was first described in 1960 (29), and the gradual improvements introduced in the work environments hereafter favors a peak in incidence rates around the year 1995. If the asbestos consumption is considered an estimate of asbestos exposure level and an average latency of 35 years is used, the maximal incidence rate cannot be expected until the year 2010 .

The fit of the model using period of diagnosis being the better of the 2 models used calls for some caution in interpreting the results of the predictions made by using the birth cohort in the analysis. The period of diagnosis cannot readily be utilized in calculating the future number of cases of malignant mesothelioma because of nonexisting reliable predictions of future asbestos exposure. Prior exposure can only be quantified by the total consumption of asbestos, which is a very rough estimate of the individual exposure to asbestos. The asbestos imported after the ban has comprised chrysotile fibers, used for brakes and pipefittings, while the import of amphiboles has been completely banned $(4,5)$. Information on the distribution of the different fiber types, relevant to the risk of mesothelioma, is not available, not even for amphiboles and serpentine fibers.

If a prediction of the future number of mesothelioma cases were to be carried out on the basis of an analysis of the period of diagnosis and age, it would be essential to have reliable estimates of future environmental exposure levels to asbestos. These estimates cannot be made within the limits of this study.

In conclusion, with careful interpretation of the results, the annual number of malignant mesothelioma cases can be expected to increase steadily until 2010 . No or little effect of banning the usage of asbestos can be expected until 2015 or later.

\section{Acknowledgments}

We wish to thank statistician Gerda Engholm, Statistics Denmark, for doing the statistical modeling of the data and introducing the idea of trying the effect of age and period of diagnosis. Statisticians Birthe Lykke Thomsen and Mette Suntum, Danish Cancer Society, have been helpful in interpreting the results.

Financial support for the statistical analyses was provided by the Danish Cancer Society, grant 5622312/9172.

\section{References}

1. Storm HH, Pihl J, Michelsen E, Nielsen AL, editors. Cancer incidence in Denmark 1993. Copenhagen: Danish Cancer Society, 1996.

2. International Agency for Research on Cancer (IARC). Asbestos. Lyon, France: IARC, 1973. Monograph on the evaluation of the carcinogenic risk of chemicals to man, vol 14.

3. Olsen JH, Andersson M. Asbestinduceret cancer i Danmark [Cancer induced by asbestos in Denmark]. Ugeskr Laeger 1986;148(49):3328-33.

4. Ministry of Labour. Arbejdsministeriets bekendtgørelse mr 660 af 24. september 1986 om asbest [Departmental order of the Ministry of Labour no 660, September 24, 1986, concerning asbestos]. Copenhagen: Ministry of Labour, 1986.

5. Ministry of Labour. Arbejdsministeriets bekendtgørelse nr 984 af 11. december 1992 [Departmental order of the Ministry of Labour no 984, 11 December 1992, concerning the usage of asbestos]. Copenhagen: Ministry of Labour, 1992.

6. Järvholm B, Englund A, Albin M. Pleural mesothelioma in Sweden: an analysis of the incidence according to the use of asbestos. Occup Environ Med 1999;56:110-3.

7. Kjaergaard J, Michelsen EV. Malignt mesoteliom: incidens, overlevelse og relativ risiko i udvalgte kommuner 1943 1992 [Malignant mesothelioma: incidence, survival and relative risks in selected municipalities 1943-1992]. Ugeskr Laeger 1997;159(31):4756-61.

8. Huncharek M. The biomedical and epidemiological characteristics of asbestos-related diseases: a review. Yale J Biol 
Med 1986;59:435-51.

9. Selikoff IJ, Hammond EC, Seidman H. Latency of asbestos disease among insulation workers in the United States and Canada. Cancer 1980;46:2736-40.

10. Storm HH, Michelsen EV, Clemmensen IH, Pihl J. The Danish Cancer Registry - history, content, quality and use. Dan Med Bull 1997;44:549-53.

11. Peto J, Decarli A, la VC, Levi F, Negri E. The European mesothelioma epidemic. Br J Cancer 1999;79(3-4):66672.

12. Ilg AG, Bignon J, Valleron AJ. Estimation of the past and future burden of mortality from mesothelioma in France. Occup Environ Med 1998;55(11):760—5.

13. Price B. Analysis of current trends in United States mesothelioma incidence. Am J Epidemiol 1997;145(3):211—8.

14. Peto J, Hodgson JT, Matthews FE, Jones JR. Continuing increase in mesothelioma mortality in Britain. Lancet 1995;345:535-9.

15. World Health Organization (WHO). Manual of the international statistical classification of diseases, injuries, and causes of death: 1955 revision (7th). Geneva: WHO, 1957.

16. World Health Organization (WHO). International classification of diseases for oncology (ICD-O). Geneva: WHO, 1976.

17. Fr $\varnothing$ rup E, Bisgaard MP, Olesen PE, editors. Statistical yearbook 1996. Copenhagen: Statistics Denmark, 1996.

18. Smith P. Comparison between registries: age-standardised rates. In: Muir C, Waterhouse J, Mack T, Powell J, Whelan S, editors. Cancer incidence in five continents, volume V. Lyon (France): International Agency for Research on Cancer (IARC), 1987:790-5. IARC scientific publications, vol 11.

19. Breslow NE, Day NE. Statistical methods in cancer research; vol II (The design and analysis of cohort studies). Lyon: International Agency for Research on Cancer (IARC), 1987. IARC scientific publications, vol 82.

20. Breslow NE, Day NE. Dawis W, editors. Statistical methods in cancer research; vol I (The analysis of case-control stud- ies). Lyon (France): International Agency for Research on Cancer (IARC), 1980. IARC scientific publications, vol 32.

21. Roush GC, Holford TR, Schymura MJ, White C. Cancer risk and incidence trends: the Connecticut perspective. Washington (DC): Hemispere Publishing Corporation, 1987.

22. Statistics Denmark. Import and export, 1910 -93. Copenhagen: Statistics Denmark, 1993.

23. Nielsen AM, Olsen JH, Madsen PM, Francis D, Almind M. Peritoneal mesotheliomas in Danish women: review of histopathologic slides and history of abdominal surgery. Acta Obstet Gynecol Scand 1994;73:581-5.

24. Petri CN. Decrease in the frequency of autopsies in Denmark after the introduction of a new autopsy act. Qual Assur Health Care 1993;5:315-8.

25. Storm HH, Andersen J. Autopsihyppighed blandt cancerpatienter i Danmark 1971-1980 [Utilisation of autopsies in cancer patients in Denmark 1971-1980]. Ugeskr Laeger $1986 ; 148: 1110-4$.

26. Andersson M, Olsen JH. Malignt mesoteliom i Danmark 1943-1990: kræftstatistik 9 [Malignant mesotheliomas in Denmark 1943-1980: cancer statistics 9]. Ugeskr Laeger 1984;146:1085-7.

27. Karjalainen A, Pukkala E, Mattson K, Tammilehto L, Vainio H. Trends in mesothelioma incidence and occupational mesotheliomas in Finland in 1960--1995. Scand J Work Environ Health 1997;23(4):266-70.

28. International Agency for Research on Cancer (IARC). Overall evaluation of carcinogenicity: an updating of IARC monographs volumes 1 to 42. Lyon (France): IARC, 1987. IARC monographs on the evaluation of carcinogenic risks to humans, suppl 7.

29. Wagner IC, Sleggs CA, Merchand P. Diffuse pleural mesothelioma and asbestos exposure in the North Western Cape Province. Br J Ind Med 1960;17:260-71.

Received for publication: 9 March 1999 